\title{
Detection and identification of hybrids in the coenopopulation of co-growing species of Cypripedium (Orchidaceae) in the Novosibirsk Region
}

\author{
Elena Zhmud ${ }^{l^{*}}$, Aleksandra Nabieval, Irina Kuban ${ }^{l}$, Natasha Williams², and Olga \\ Dorogina $^{l}$ \\ ${ }^{1}$ Central Siberian botanical garden SB RAS 630090, Novosibirsk, Zolotodolinskaya str., 101. Russia \\ ${ }^{2}$ Department of Health and Exercise Science, Moby Complex, Campus 1582, Colorado State \\ University, Fort Collins, Colorado, 80523. USA
}

\begin{abstract}
Cypripedium calceolus L. and C. macranthon Sw. (Orchidaceae) are rare species throughout almost the entire territory of Russia. Though the data on intraspecific genetic differentiation has been presented in the literature, the species of $C$. calceolus, C. macranthon and alleged hybrids of $C$. $\times$ ventricosum growing in sympatric population in the Iskitim District of the Novosibirsk Region (NR) have not been investigated yet. The purpose of this work is dentification of the rare species of Cypripedium calceolus, C. macranthon and detection of $C . \times$ ventricosum hybrids in the NR using morphometric parameters and ISSR markers. It was found the mature generative specimens of $C . \times$ ventricosum formed the largest number of shoots, compared with the parent species. According to the number of flowers on the generative shoot, the hybrid occupied an intermediate position. According to the ISSR analysis, components from both parental species were identified in each of the three hybrids studied. Therefore, the presence of $C . \times$ ventricosum hybrid plants in the local NR coenopopulation of co-growing species $C$. calceolus and C. macranthon was detected and confirmed based on the study of morphometric parameters and ISSR markers.
\end{abstract}

\section{Introduction}

Almost throughout the whole territory of Russia, Cypripedium calceolus L. and C. macranthon Sw. (Orchidaceae) are rare species declining in number as a result of changes in the conditions of existence and destruction of habitats. These species are included in the Red Book of the Russian Federation with a status of 2a [1]. According to published data, in the area of $C$. calceolus and C. macranthon overlap, their hybrid $C$. $\times$ ventricosum occurs, though rarealy. Some authors report the morphoological characteristics of $C . \times$ ventricosum to be intermediate between the parental species $[2,3]$. On the territory

\footnotetext{
* Corresponding author: elenazhmu@,ngs.ru
} 
of Siberia and the Far East, this species is listed as rare in the Red Books of the Amur and Jewish Autonomous Regions and the Republic of Sakha (Yakutia) [4, 5, 6]. In spite of the available data on the intraspecific genetic differentiation obtained using ISSR markers for the representatives of Cypripedium genus [7, 8], the species C. calceolus, C. macranthon and assumed hybrid $C$. $\times$ ventricosum growing in the Novosibirsk Region (NR) have not beens tudied yet. The purpose of this work is to use the morphometric parameters and ISSR markers to identify rare species of Cypripedium calceolus, C. macranthon and reveal their hybrids $C$. $\times$ ventricosum in the sympatric population.

\section{Materials and methods}

The population under study is located in the Iskitim District of the NR, in the vicinity of Linevo settlement, in the floodplain of the river Koynikha. The absolute altitude is $190 \mathrm{~m}$ above the sea level, geographic coordinates are N 54.027'42"; E 83.020'42”. In 2019, we carried out morphometric studies of selectively sampled generative shoots of individuals in the flowering phase from one of each parcel bush, $n=10$ ) in the species of the Cypripedium genus from the area occupied by the cenopopulation (CP) (more than 1 thousand sq. m). Metric indicators of the generative organs were studied: the size of the sepal of the flowers and the second leaf from top (length and width), the variability of the length of the generative shoot, the number of flowers on the shoot, number of shoots of an individual (vegetative and generative), and fruit formation rate (the ratio of set fruit to the total number of formed ones, in per cent), in particular to reveal the signs probably prone to heterosis. Only the values of signs significantly different from each other in terms of statistics, at a significance level of at least $95 \%(\mathrm{P}=95 \%)$. are discussed in the article. The reliability of differences in average values of signs was evaluated according to nonparametric criteria [9]. For identification using ISSR markers, DNA was isolated from the leaves of $C$. calceolus, C. macranthon, $C$. $\times$ ventricosum, dried under laboratory conditions. The leaves were collected from three individuals of each species in the flowering phase. STAB-based DNA extraction with some modifications was carried out [10]. For preliminary testing, 11 ISSR primers were used. After testing, 4 of the most informative ones were selected. They were characterized by a clear, reproducible, polymorphic pattern: 17898A, 17899A, HB-10, M-1 (table).

Table Characterization of ISSR primers

\begin{tabular}{|c|c|c|c|c|}
\hline $\begin{array}{c}\text { Nucleotide } \\
\text { sequence } \\
\mathbf{5}^{\prime}-\mathbf{3}^{\prime}\end{array}$ & Primer & $\begin{array}{c}\text { Temperature, } \\
{ }^{\mathbf{}} \mathbf{C}\end{array}$ & $\begin{array}{c}\text { Total (polymorphic) } \\
\text { fragments }\end{array}$ & Polymorphism \\
\hline$(\mathrm{CA})_{6} \mathrm{AC}$ & $17898 \mathrm{~A}$ & 42 & $23(21)$ & 91.3 \\
\hline$(\mathrm{CA})_{6} \mathrm{AG}$ & $17899 \mathrm{~A}$ & 47 & $15(14)$ & 93.3 \\
\hline$(\mathrm{GA})_{6} \mathrm{CC}$ & $\mathrm{HB}-10$ & 44 & $12(10)$ & 83.3 \\
\hline$(\mathrm{AC})_{8} \mathrm{CG}$ & $\mathrm{M}-1$ & 56 & $9(8)$ & 88.9 \\
\hline
\end{tabular}

Electrophoretic separation of amplification products in $1.5 \%$ agarose gel in $1 \mathrm{x}$ TAE buffer at a voltage of $4 \mathrm{~V} / \mathrm{cm}$ was carried out. Statistical processing of the data was carried out with the TREECON software package [11]. Genetic distances were calculated according to Nei [12]. The level of polymorphism (P, \%) of each primer was calculated using the formula $\mathrm{P}=100 * \mathrm{~Np} / \mathrm{N}$, where $\mathrm{Np}$ is the number of polymorphic fragments, and $\mathrm{N}$ is the total number of fragments. 


\section{Results and discussion}

Individuals of the three studied species of Cypripedium in this $\mathrm{CP}$ were qualitatively different in terms of pubescence of shoots, which is a well-known marker characteristic of the species [13]. Morphometric studies (length and width, $\mathrm{cm}$ ) showed that the average size of the flower sepal in the individuals of $C$. calceolus was significantly smaller than in $C$. macranthon and $C$. $\times$ ventricosum $(3.2 \pm 0.1 \times 2.3 \pm 0.1$ and $4.1 \pm 0.2 \times 3.7 \pm 0.2$, respectively) $(\mathrm{P}$ $=95 \%$ ). The size (in $\mathrm{cm}$ ) of the second leaf from the top in C. macranthon, in comparison with two other studied species of this genus, is smaller in this CP: $(10.9 \pm 0.6 \times 6.0 \pm 0.3$ for $C$. macranthon; $14.9 \pm 0.7 \times 7.8 \pm 0.5$ and $14.3 \pm 0.8 \times 8.7 \pm 0.6$ in $C$. calceolus and $C$. $\times$ ventricosum $)(\mathrm{P}=95 \%)$. The shoots in the individuals of $C$. calceolus and $C . \times$ ventricosum were longer than in $C$. macranthon $(35.8 \pm 1.9,34.2 \pm 1.6$, and $24.5 \pm 0.4 \mathrm{~cm}$, respectively). In most individuals of $C$. calceolus, 2 flowers $(1.7 \pm 0.2)$ were formed on each generative shoot, and in $C$. macranthon, only one was formed. In $C . \times$ ventricosum, the intermediate value of this trait was noted (1.2 \pm 0.1$)$. Representatives of $C . \times$ ventricosum differed by the high potential productivity, which was expressed as large clumps with a large number of shoots (both generative and vegetative). So, in $C$. $\times$ ventricosum, on average, $21.2 \pm 7.6$ generative and $5.0 \pm 1.2$ vegetative shoots were detected. This is significantly more than the corresponding number for C. calceolus and C. macranthon (7.2 $\pm 2.2,0.9 \pm 0.4$ and $3.7 \pm 0.8$ and $2.2 \pm 0.8$, respectively) $(\mathrm{P}=95 \%)$. The development of a large number of shoots in $C$. $\times$ ventricosum was also detected previously in the Middle Urals. It is likely that this phenomenon may be a consequence of the heterosis effect [2]. At the same time, according to our data, $C$. $\times$ ventricosum was characterized by lower fruit productivity. The average number of fruit in $\mathrm{C}$. $\times$ ventricosum was $25.2 \pm 8.4$. In $C$. calceolus and $C$. macranthon, it was $74.8 \pm 5.6$ and $82.6 \pm 8.7$, respectively. Reduced pollen fertility may be the reason of this. This was revealed in the studies of the causes of low fruit setting in $C . \times$ ventricosum in the Middle Urals [2]. Thus, in this population in NR, significant differences between $C$. $\times$ ventricosum and two other Cypripedium species were determined. In the representatives of $C$. $\times$ ventricosum, the formation of the largest number of generative shoots and the lowest fruit setting per individual were found. The number of flowers on the generative shoot of $C$. $\times$ ventricosum is intermediate. The similarity of the individuals of $C$. $\times$ ventricosum with $C$. calceolus is in the formation of longer shoots and larger size of the second leaf from top, and the similarity with C. macranthon is in larger sepal sizes $(\mathrm{P}=95 \%)$.

The dendrogram shown in Fig. 1 was built up according to the results of ISSR analysis. It is clearly visible that 3 clades correspond to 3 species. These species are characterized by the least genetic similarity. In this case, the individuals of $C$. calceolus are characterized by the highest genetic homogeneity, and $C . \times$ ventricosum - by the lowest one, in comparison with the other two species.

The analysis of molecular genetic markers on the four obtained electrophoregrams revealed 59 fragments. 53 of them were polymorphic. The number of fragments amplified by one primer varied from 9 (M-1) to 23 (17898A). The level of polymorphism during amplification varied from $83.3 \%$ (HB-10) to $93.3 \%$ (17899A) (Fig. 2).

The electrophoretic spectra of hybrid individuals No. 1 and No. 2 contained the components from two parental forms: 1-3 common components from three C. calceolus individuals and 2 to 5 common components with C. macranthon individuals (No. 7, No. 8) were identified. In hybrid specimen No. 3, components 2 and 4 similar to C. macranthon were present in the spectrum. Also, in this individual, 1 and 3 common components with individuals No. 4 and No. 6 (C. calceolus), respectively, were identified. No common components with specimen No. 5, were observed in this hybrid plant (Fig. 2). Thus, in the 
electrophoretic spectra of all hybrid individuals of $C . \times$ ventricosum, the components from almost each of the parental individuals were present.

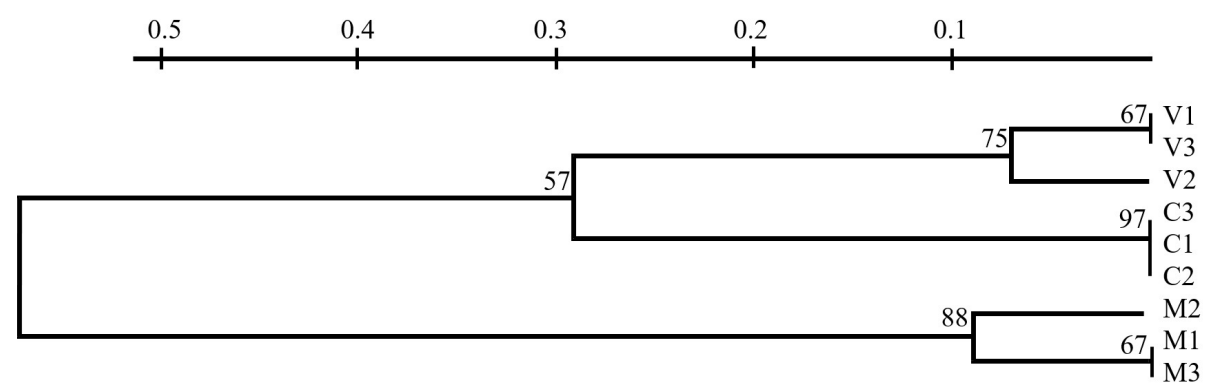

Fig. 1. A dendrogram based on the neighbor-joining (NJ) method is constructed, and the relationship between the species of the Cypripedium genus (Orchidaceae) is reflected. The scale above is the genetic distance according to Nei (1979). The numbers above the nodes show the level of statistical support for the branches (more than 50\%). Designations: V1-V3 - Cypripedium $\times$ ventricosum; $\mathrm{C} 1-$ C3 - C. calceolus; M1-M3 - C. macranthon.

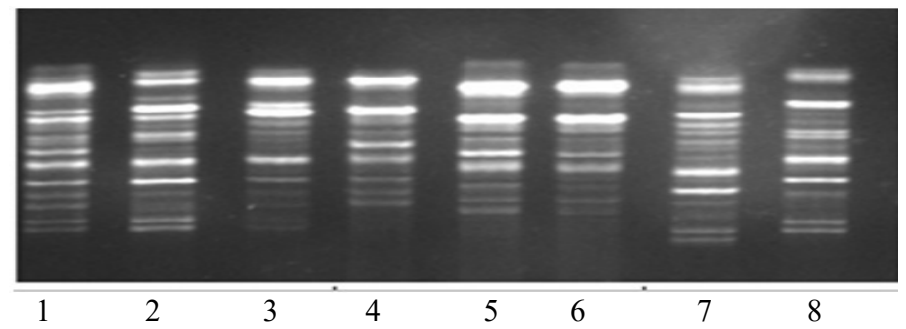

Fig. 2. Electrophoretic spectra of ISSR markers in the species of the Cypripedium genus from the Novosibirsk region (2019). Designations: 1-3 - Cypripedium $\times$ ventricosum; 4-6 - C. calceolus; 7-8 C. macranthon.

\section{Conclusion}

In the sympatric population in the NR, the presence of two species of the Cypripedium genus (C. calceolus and C. macranthon) and their hybrid, $C$. $\times$ ventricosum, was confirmed by us. By the number of flowers on the generative shoot, the hybrid occupies an intermediate position. Sepal sizes are similar to those of $C$. macranthon. By the size of the leaf blade, $C$. $\times$ ventricosum was similar to $C$. calceolus. The mature generative specimens of $C . \times$ ventricosum formed the largest number of shoots, compared with the parent species. This phenomenon may be due to heterosis and may contribute to the strengthening of its coenotic role. The ISSR analysis showed that in each of the three hybrids studied, components from C. calceolus are present, and in two of them, components from both parent species were identified.

Thus, on the basis of comparative studies of the morphometric parameters and ISSR markers in the local cenopopulation in the NR, the presence of $C$. $\times$ ventricosum hybrid plants was detected and confirmed.

The work was carried out within the framework of the State Assignment for the Central Siberian Botanical Garden SB RAS No. AAAA-A17-117012610051-5 on the project "Assessment of the morphogenetic potential of plant populations in North Asia by experimental methods". 


\section{References}

1. Red Data Book of the Russian Federation (plants and fungi) (2008)

2. M.C. Knyazev, P.V. Kulikov, O.I. Knyazeva, V.L. Semerikov, Bot. Zhurn. 85, 5 (2000)

3. E. Andronova, E. Machs, E. Filippov, Genetic polymorphism of Cypripedium calceolus, C. macranthon, C. shanxiense, C. x ventricosum (Orchidaceae) inferred from pyrosequencing data in Proceeding of the conference on Problems of botany of Southern Siberia and Mongolia, 23-26 may 2016, Barnaul, Russia (2016)

4. Red Book of the Amur Region, https://cicon.ru/krasnaya-kniga-amurskoiobl.html Accessed 11. 2019

5. Red Data Book of the Jewish Autonomous Region, Rare and Endangered Species of Plants and Mushrooms (2006)

6. The Red Book of the Republic of Sakha (Yakutia). Rare and endangered species of plants and mushrooms (2017)

7. A. Opitz, Populationsgenetische Untersuchungen an hessischen Populationen von Cypripedium calceolus L. Dissertation, Institut für Botanik, November 2016. http://geb.unigiessen.de/geb/volltexte/2017/12491/pdf/OpitzAndreas_2017_02_14.pdf

8. H.Z. Tian, L.X. Han, J.L. Zhang, X.L. Li, T. Kawahara, T. Yukawa, J. López-Pujol, P. Kumar, M.G. Chung, M.Y. Chung, Scientific Reports. 8, 1 (2018)

9. H.B. Mann, D.R. Whitney, Ann. Math. Stat. (1947)

10. J.J. Doyle, J.L. Doyle, Phytochemistry Bull. 19 (1987)

11. V.Y. Peer, R.D. Wachter, Comput. Appl. Biosci. 10:569-570 (1994)

12. M. Nei, W.H. Li, Proc. Nat. Acad. Sci. USA. 76, 10 (1979)

13. L.V. Averyanov, Turczaninovia. 2, 2 (1999) 